\title{
Development of a novel niosomal system for oral delivery of Ginkgo biloba extract
}

This article was published in the following Dove Press journal:

International Journal of Nanomedicine

23 January 2013

Number of times this article has been viewed

\author{
Ye Jin ${ }^{1,4}$ \\ Jingyuan Wen ${ }^{2}$ \\ Sanjay Garg ${ }^{3}$ \\ Da Liu' \\ Yulin Zhou' \\ Lirong Tengl,* \\ Weiyu Zhang ${ }^{4, *}$ \\ 'College of Life Science, Jilin \\ University, Jilin, People's Republic \\ of China; ${ }^{2}$ School of Pharmacy, \\ Faculty of Medical and Health \\ Sciences, University of Auckland, \\ Auckland, New Zealand; ${ }^{3}$ School \\ of Pharmacy and Medical Sciences, \\ University of South Australia, \\ Adelaide, Australia; ${ }^{4}$ School of \\ Pharmacy, Changchun University \\ of Chinese Medicine, Jilin, People's \\ Republic of China
}

*These authors contributed equally to this work

Correspondence: Lirong Teng College of Life Science, Jilin University, 2699 Qianjin Street, Changchun I300 I2, Jilin, China

Tel +8643185168646

Fax +8643185168637

Email tenglirong@jlu.edu.cn
Background: The aim of this study was to develop an optimal niosomal system to deliver Ginkgo biloba extract (GbE) with improved oral bioavailability and to replace the conventional GbE tablets.

Methods: In this study, the film dispersion-homogenization method was used to prepare GbE niosomes. The resulting GbE niosome suspension was freeze-dried or spray-dried to improve the stability of the niosomes. GbE-loaded niosomes were formulated and characterized in terms of their morphology, particle size, zeta potential, entrapment efficiency, and angle of repose, and differential scanning calorimetry analysis was performed. In vitro release and in vivo distribution studies were also carried out.

Results: The particle size of the optimal delivery system prepared with Tween 80 , Span 80 , and cholesterol was about $141 \mathrm{~nm}$. There was a significant difference $(P<0.05)$ in drug entrapment efficiency between the spray-drying method (about 77.5\%) and the freeze-drying method (about $50.1 \%$ ). The stability study revealed no significant change in drug entrapment efficiency for the $\mathrm{GbE}$ niosomes at $4^{\circ} \mathrm{C}$ and $25^{\circ} \mathrm{C}$ after 3 months. The in vitro release study suggested that $\mathrm{GbE}$ niosomes can prolong the release of flavonoid glycosides in phosphate-buffered solution ( $\mathrm{pH}$ 6.8) for up to 48 hours. The in vivo distribution study showed that the flavonoid glycoside content in the heart, lung, kidney, brain, and blood of rats treated with the GbE niosome carrier system was greater than in the rats treated with the oral GbE tablet $(P<0.01)$. No flavonoid glycosides were detected in the brain tissue of rats given the oral GbE tablets, but they were detected in the brain tissue of rats given the GbE niosomes.

Conclusion: Niosomes are a promising oral system for delivery of GbE to the brain.

Keywords: Ginkgo biloba extract, flavonoid glycosides, niosomes, oral delivery, in vivo distribution

\section{Introduction}

Ginkgo biloba is a plant which has existed on earth for more than 200 million years and is considered to be a "living fossil". ${ }^{1}$ G. biloba extract (GbE) is extracted from dry G. biloba leaves and purified to a light yellow powder. It is reported to have several properties beneficial to health, including scavenging radical, ${ }^{2}$ auto-oxidation, ${ }^{3}$ antitumor, ${ }^{4}$ and protective effects in the central nervous system. ${ }^{5} \mathrm{GbE}$ is now widely used in the treatment of cerebrovascular insufficiency and peripheral circulation disorders, including Alzheimer's disease, ${ }^{6}$ senile dementia, ${ }^{7}$ and tinnitus. ${ }^{8}$ The positive effects of $\mathrm{GbE}$ are based on the synergistic action of two well defined components, ie, flavonoid glycosides and terpene lactones. ${ }^{9}$ According to the Federal Institute for Drugs and Medical Devices of Germany Commission E, the ideal GbE is standardized to a $24 \%$ content of 
flavonoid glycosides, which are the key components for free radical scavenging, and a $6 \%$ content of terpene lactones which are potent antiplatelet factor antagonists. ${ }^{10}$

Although GbE has many beneficial effects in cerebrovascular disease, oral administration of the currently marketed products presents several challenges, including low bioavailability ( $<10 \%$ ), the short half-life (2.1 hours) of flavonoid glycosides in vivo, ${ }^{11}$ and the physical problem of delivering a drug across the blood-brain barrier. Hence, a number of researchers are focusing on how to enhance the action of $\mathrm{GbE}$ by developing advanced drug delivery systems. Yamamoto et al found an increased inhibitory effect of $\mathrm{GbE}$ on tumor cell growth when GbE was encapsulated in hybrid liposomes. ${ }^{12}$ Also, Chen et al prepared GbE phospholipid complexes for the purpose of increasing the bioavailability of the extract. ${ }^{13}$ It is of note that using colloidal carriers such as liposomes and niosomes generally increases diffusion of drugs through biological membranes and also protects drugs against enzymatic degradation, thereby improving drug bioavailability. Moreover, colloidal systems allow normally nontransportable drugs to cross the blood-brain barrier by masking their physical and chemical characteristics through encapsulation. ${ }^{14}$

Liposomes prepared using a variety of phospholipids were introduced in 1965 and have since been extensively studied as drug carriers and delivery systems. ${ }^{15}$ Niosomes are nonionic surfactant-based vesicles with a similar structure to that of liposomes and can carry both hydrophilic and hydrophobic drugs within the same system. ${ }^{16}$ Further, niosomes are now being studied widely as an alternative to liposomes because they can overcome the limitations associated with liposomes, ie, chemical instability, variable purity of the phospholipid content, and high cost. ${ }^{17}$ Niosomes are currently used as versatile drug delivery systems with many pharmaceutical applications, including for oral, ${ }^{18}$ pulmonary, ${ }^{19}$ transdermal,,${ }^{20}$ protein and peptide, ${ }^{21}$ gene, ${ }^{22}$ and vaccine delivery. ${ }^{23}$

The aim of the present study was to develop a niosomal formulation as a new oral carrier for $\mathrm{GbE}$. A factorial design was used to optimize the $\mathrm{GbE}$ niosome formulation in terms of particle size and drug entrapment efficiency. Freeze-drying and spray-drying methods were used to prepare a $\mathrm{GbE}$ niosome powder to ensure stability of the extract and improve patient compliance. Characteristics of the niosomes, including their morphology, particle size, zeta potential, entrapment efficiency, and angle of repose were evaluated. The interactions between $\mathrm{GbE}$ and niosomes were also studied by differential scanning calorimetry (DSC). To characterize the release profile of flavonoid glycosides from GbE niosomes, three types of release medium (phosphate buffer at $\mathrm{pH} 6.8$, acetic acid solution at $\mathrm{pH} 4.0$, and hydrochloric acid solution at $\mathrm{pH} 1.0$ ) were used in an in vitro release study. A GbE niosome stability study was carried out to evaluate the change in entrapment efficiency at two temperatures $\left(4^{\circ} \mathrm{C}\right.$ and $\left.25^{\circ} \mathrm{C}\right)$ for 3 months. In vivo distribution of the $\mathrm{GbE}$ niosomes was investigated after oral administration to rats, and tissue samples were analyzed using high-pressure liquid chromatography (HPLC) to determine the drug content in various organ systems.

\section{Materials and methods Materials}

GbE containing Ginkgo flavonoid glycosides $\geq 24 \%$ and terpene lactones $\geq 6 \%$ was obtained from Jinmei Kang Co (Xuzhou, China). The reference standards for flavonoid glycosides (quercetin, kaempferide, and isoquercitrin) were purchased from the National Institute for the Control of Pharmaceutical and Biological Products (Beijing, China). Polysorbate 80 (Tween 80), sorbitan mono-oleate (Span 80), cholesterol, and mannitol were supplied by Sigma-Aldrich (St Louis, MO). Acetonitrile and methanol of HPLC grade were purchased from Ajax Finechem Pty Ltd (Auckland, New Zealand). Dichloromethane, sodium acetate, hydrochloric acid, potassium dihydrogen phosphate, phosphoric acid, acetic acid, ethyl ether, and ethanol were sourced from Scharlau (Barcelona, Spain).

\section{HPLC analysis of GbE flavonoid glycosides}

An HPLC system (LC-10ATVP HPLC, Shimadzu, Tokyo, Japan) equipped with a ternary pump, an injector with a $20 \mu \mathrm{L}$ loop, and an ultraviolet-visible detector (SPD-10AVP, Shimadzu, Tokyo, Japan) was used, with data acquisition by N2000 software (University of Zhejiang, Zhejiang, China). Separation and quantitation were achieved using an Agilent HC-C18 column $(250 \times 4.6 \mathrm{~mm}, 5 \mu \mathrm{m}$; Agilent Corporation, Santa Clara, CA) fitted with a C18 guard column $(10 \times 3.0 \mathrm{~mm})$. The mobile phase was prepared by mixing 28 parts $(\mathrm{v} / \mathrm{v})$ of acetonitrile and 72 parts of Milli-Q (Millipore, Billerica, MA) water (v/v) containing $0.4 \%(\mathrm{v} / \mathrm{v})$ phosphoric acid. The analysis was performed at $40^{\circ} \mathrm{C}$ at an isocratic flow rate of $1.0 \mathrm{~mL}$ per minute, and analytes were detected at a wavelength of $360 \mathrm{~nm}$. The retention times of each flavonoid glycoside (quercetin, kaempferide, and isoquercitrin) were $15.95,30.72$, and 33.35 minutes, respectively. The total run time was 35 minutes.

\section{Optimization of niosomal formulation}

Based on the results of initial experiments, our niosomes were prepared using the film dispersion-homogenization 
method $^{24}$ with some modification. A range of process variables, including hydrophile-lipophile balance values for the surfactants, hydration temperature, molar ratio of surfactants, and cholesterol and weight ratio of GbE and carriers, were studied and optimized on the basis of uniformly small particle size and high entrapment efficiency. A surfactant mixture (Tween 80 and Span 80) and cholesterol were dissolved in $80 \mathrm{~mL}$ of methanol/dichloromethane $(3: 1, \mathrm{v} / \mathrm{v})$ in a round bottom flask. The solvent was evaporated at $37^{\circ} \mathrm{C}$ under vacuum by a rotary evaporator (RE-52A, Yarong Biochemistry Apparatus Ltd, Shanghai, China). The resulting dried film was redissolved in $60 \mathrm{~mL}$ of ethyl ether, and a solution containing $\mathrm{GbE}$ in a mixture of dehydrated alcohol and phosphate-buffered solution (pH 6.5) was then added. Next, $20 \mathrm{~mL}$ of phosphate-buffered solution was added after 10 minutes of sonication. Rotary evaporation was performed again at $60^{\circ} \mathrm{C}$ until hydration was achieved and the residual ethyl ether was removed. The niosomal suspension was left to mature overnight at $30^{\circ} \mathrm{C}$ in a thermostatic water bath shaker. In order to obtain a uniform particle size, the niosomal suspension was homogenized using a high pressure homogenizer (NS1001L2K, Niro Soavi Ltd, Italy).

\section{Preparation of niosomal powder}

Powder-derived niosomes are superior to conventional niosomes in terms of convenience of storage, transport, and dosing. ${ }^{25}$ To prevent degradation, fusion, and leakage, the niosomal powder was prepared using freeze-drying and spray-drying method. Mannitol was added into the niosomal suspension as a protectant to prevent drug leakage upon dehydration using each drying method. Six grams of mannitol was added into $100 \mathrm{~mL}$ of niosomal suspension before each drying method was performed.

\section{Freeze-drying method}

Niosomal powder was prepared using a modification of the freeze-drying technique reported by Mukherjee et al. ${ }^{26}$ After overnight prefreezing at $-80^{\circ} \mathrm{C}$, the primary drying was done using a vacuum freeze-dryer (Christ Alpha 1-4, Palaiseau Cedex, France) for 24 hours.

\section{Spray-drying method}

The spray-drying process was done using a spraydryer (Büchi B 290, Büchi Labortechnik AG, Flawil, Switzerland). The niosomal suspension was fed to the spray chamber by a pump. The aspirator setting, airflow rate, inlet temperature, and speed of the pump were kept at the scale of $100 \%, 357 \mathrm{~L} /$ hour, $130^{\circ} \mathrm{C}$, and $1.5 \mathrm{~mL} /$ minute, respectively. Finally, the resulting powder was separated from the hot air stream with cyclone and collected in the bottom of the chamber.

\section{Characterization of GbE niosomes}

\section{Morphology}

The morphology of the niosomes was studied by scanning electron microscopy. Ten milligrams of niosomal powder was redispersed in $1 \mathrm{~mL}$ of Milli-Q water, and $10 \mu \mathrm{L}$ of the suspension was then added on top of a conductive double-sided adhesive tape mounted on an aluminum stub. The samples were air-dried for 2 hours and then coated with platinum. Samples were observed using a scanning electron microscope (XL30S FEG, Philips, Eindhoven, The Netherlands) at 5-25 kV under high vacuum.

\section{Niosomal size and zeta potential}

The particle size and size distribution of the prepared niosomes were determined by light scattering based on laser diffraction using a particle size analyzer (LS13320, Beckman Coulter Inc, Fullerton, CA). ${ }^{27}$ The zeta potential was considered to be an indicator of the surface potential of the niosome, and was measured using a Zetasizer (Malvern Instruments, Worcestershire, UK).

The particle size and zeta potential of the niosomes were measured immediately after preparation and then after drying to powder in order to observe the effects of each drying method on these parameters.

\section{Entrapment efficiency of flavonoid glycosides}

The proportion of non-trapped flavonoid glycosides was determined to assess entrapment efficiency. To separate the non-trapped flavonoid glycosides, the niosomal suspension was ultracentrifuged (Sorvall WX8, Hemel Hempstead, UK) at 91,580 $\mathrm{g}$ and $4^{\circ} \mathrm{C}$ for one hour. After centrifugation, the amount of flavonoid glycoside content in the supernatant was analyzed using the HPLC method. Further, the GbE niosome powder was washed twice in methanol and the non-trapped flavonoid glycosides were then separated by centrifugation at $3663 \mathrm{~g}$ for 10 minutes at $4^{\circ} \mathrm{C}$. The amount of non-trapped flavonoid glycosides in the supernatant was analyzed using the HPLC method.

Entrapment efficiency was calculated using the following equation: ${ }^{28}$ Flavonoid glycoside
entrapment efficiency $(\%)=\left(1-\frac{A_{u}}{A_{0}}\right) \times 100$ 
where $\mathrm{A}_{0}$ is the initial amount of flavonoid glycosides used in the preparation and $\mathrm{A}_{\mathrm{u}}$ is the amount of non-trapped flavonoid glycosides detected in the supernatant.

\section{Angle of repose}

The angle of repose is an indicator of flow ability and was measured in the niosomal powder by a fixed-cone tank method. ${ }^{29}$ The powder was poured into three fixed funnels arranged from top to bottom. A watch glass with a radius of $2 \mathrm{~cm}$ was set at the bottom so that the falling powder could be collected on the watch glass and stacked into a circular cone. The height of the highest circular cone was recorded and the angle of repose was then calculated by measuring the height of the cone and the diameter of its base.

\section{Differential scanning calorimetry analysis}

Differential scanning calorimetry is a basic method used to provide information about the thermal behavior, structure changes, and interaction between a drug and other materials. ${ }^{30}$ To perform the DSC analysis, a small amount of sample was sealed in an aluminum crucible. ${ }^{21}$ A second blank aluminum crucible was sealed as the reference. The temperature of the pans was raised from $25^{\circ} \mathrm{C}$ to $300^{\circ} \mathrm{C}$ in a nitrogen atmosphere at the rate of $10^{\circ} \mathrm{C}$ per minute. The flow rate of nitrogen was $50 \mathrm{~mL}$ per minute (Mettler-Toledo STARe, Greifensee, Switzerland). ${ }^{13}$ The heat flow calibration was performed with indium. The peak transition onset temperatures of GbE, cholesterol, mannitol, and $\mathrm{GbE}$ niosomes were determined and compared in order to demonstrate the constitution of GbE niosomes.

\section{In vitro release of flavonoid glycosides from niosomes}

The release of flavonoid glycosides from niosomes in different types of release medium (phosphate buffer at pH 6.8, acetic acid solution at $\mathrm{pH} 4.0$, and hydrochloric acid solution at $\mathrm{pH}$ 1.0) was determined by the dialysis method using cellulose acetate dialysis tubing (molecular cutoff 8000-10,000) sealed at both ends with clips. ${ }^{31}$ Niosomal powder and $10 \mathrm{~mL}$ of release medium were placed in the dialysis bag, which was then transferred into $90 \mathrm{~mL}$ of release medium. The release system was constantly stirred and the temperature was kept at $37^{\circ} \mathrm{C} \pm 1^{\circ} \mathrm{C}$ throughout the study. A $5 \mathrm{~mL}$ aliquot was withdrawn at regular time intervals and replaced with the same volume of fresh release medium. Samples were then analyzed using the HPLC method.

To investigate release kinetics and calculate the release rate, the release data were fitted into various models, including zero-order $\left(Q_{t}=Q_{0}+K t\right)$, first-order $\left(\log Q_{t}=\log Q_{0}+K t\right)$, Higuchi $\left(Q_{t} / Q_{\infty}=K t^{1 / 2}\right)$, and Korsmeyer-Peppas models $\left(Q_{t} / Q_{\infty}=K t^{n}\right)$, where $Q_{t}$ denotes cumulative drug release at time $t$ and $K$ is the release rate constant, $Q_{0}$ is the initial amount of drug in the solution, and $Q_{\infty}$ is the cumulative drug release at time $\infty$. The release data were fitted to the model by linear regression analysis using Microsoft Excel 2007 version 3.0.

\section{Stability studies}

The ability of niosomes to retain the drug (drug retention behavior) was studied by keeping the niosomal powder formulations at two different temperatures, ie, refrigeration temperature $\left(4^{\circ} \mathrm{C}-8^{\circ} \mathrm{C}\right)$ and room temperature $\left(25^{\circ} \mathrm{C} \pm 2^{\circ} \mathrm{C}\right)$. Samples were stored in glass vials for 3 months and were withdrawn at regular time intervals. The entrapment efficiency of the niosomal formulation was analyzed in order to evaluate its stability properties.

\section{Evaluation of in vivo distribution of $\mathrm{GbE}$ niosomes in a rat model}

Twenty male Wistar rats $(200 \pm 20 \mathrm{~g})$ were randomly divided into two groups. One group of rats was given the $\mathrm{GbE}$ niosome formulation and the second group of rats was given

Table I Characterization of GbEN formulations by measuring entrapment efficiency and particle size (mean \pm SD, $\mathrm{n}=3$ )

\begin{tabular}{|c|c|c|c|c|c|c|}
\hline $\begin{array}{l}\text { Formulation } \\
\text { No }\end{array}$ & $\begin{array}{l}\text { HLB } \\
\text { value }\end{array}$ & $\begin{array}{l}\text { Hydration } \\
\text { temperature }\left({ }^{\circ} \mathrm{C}\right)\end{array}$ & $\begin{array}{l}\text { Ratio (mol/mol) } \\
\text { (surfactant: } \\
\text { cholesterol) }\end{array}$ & $\begin{array}{l}\text { Ratio (w/w) (GbE: } \\
\text { carriers) }\end{array}$ & $\begin{array}{l}\text { Entrapment } \\
\text { efficiency (\%) }\end{array}$ & $\begin{array}{l}\text { Mean particle } \\
\text { size }(\mathrm{nm})\end{array}$ \\
\hline $\mathrm{FI}$ & 11.0 & 60 & $\mathrm{I}: 0.5$ & $9: 100$ & $57.7 \pm 3.8$ & $142.8 \pm 19.1$ \\
\hline F2 & 11.5 & 70 & $\mathrm{I}: 0.5$ & $12: 100$ & $44.1 \pm 2.9$ & $144.9 \pm 15.6$ \\
\hline F3 & 12.0 & 80 & $\mathrm{I}: 0.5$ & $15: 100$ & $46.3 \pm 1.2$ & $140.9 \pm 18.0$ \\
\hline $\mathrm{F} 4$ & 11.0 & 60 & $\mathrm{I}: 0.75$ & $12: 100$ & $47.3 \pm 2.0$ & $4 \mid 0.1 \pm 20.3$ \\
\hline F5 & 11.5 & 60 & $\mathrm{I}: 0.75$ & $15: 100$ & $44.7 \pm 1.8$ & $283.6 \pm 21.2$ \\
\hline F6 & 12.0 & 70 & $\mathrm{I}: 0.75$ & $9: 100$ & $38.7 \pm 2.9$ & $144.0 \pm 7.7$ \\
\hline F7 & 11.0 & 70 & $\mathrm{I}: \mathrm{I}$ & $15: 100$ & $54.4 \pm 5.7$ & $505.1 \pm 49.5$ \\
\hline F8 & 11.5 & 80 & $\mathrm{I}: \mathrm{I}$ & $9: 100$ & $5 \mathrm{I} . \mathrm{I} \pm 4.4$ & $163.4 \pm 10.6$ \\
\hline F9 & 12.0 & 80 & I:I & $12: 100$ & $47.7 \pm 3.1$ & $408.4 \pm 30.8$ \\
\hline FIO & 11.0 & 60 & $\mathrm{I}: \mathrm{I}$ & $15: 100$ & $50.0 \pm 1.9$ & $141.3 \pm 11.9$ \\
\hline
\end{tabular}


GbE tablets, as a single-dose oral gavage in both groups. The flavonoid glycoside content in various rat organs (heart, liver, spleen, lung, kidney, and brain) and in blood was analyzed for 3 days post dosing in each group. Plasma and organ samples $(100 \mu \mathrm{L})$ were mixed with equivalent volumes of $4 \%$ $\mathrm{HCl}$, and the mixtures were heated at $80^{\circ} \mathrm{C}$ for 30 minutes. Following this acid hydrolysis, the samples were cooled and extracted by vortex-shaking for 5 minutes with $1000 \mu \mathrm{L}$ of ethyl acetate, and then centrifuged at 15,000 $\mathrm{g}$ for 5 minutes. The supernatant $(800 \mu \mathrm{L})$ was dried at $30^{\circ} \mathrm{C}$. The residue was reconstituted in $100 \mu \mathrm{L}$ of acetonitrile, and centrifuged at $15,000 \mathrm{~g}$ for a further 10 minutes. Twenty microliters of the resulting supernatant was analyzed by HPLC.

\section{Statistical analysis}

The results were expressed as the mean \pm standard deviation $(\mathrm{n}=3)$ and the statistical analysis was performed using Statistical Package for the Social Sciences software version 17.0 (SPSS Inc, Chicago, IL). $P<0.05$ was considered to be statistically significant.

\section{Results and discussion Optimization of niosomal formulations}

Table 1 showed the entrapment efficiency and particle size results for each of the study formulations. In the pre-experiments, entrapment efficiency was low when the hydrophile-lipophile balance value was below 10, which is in accordance with a previous report of entrapment efficiency decreasing with reduction of the surfactant hydrophilelipophile balance. ${ }^{32}$ Increasing the hydrophile-lipophile balance value to $>12$ did not improve the entrapment efficiency. Because higher hydrophile-lipophile balance values reflect a low hydrocarbon chain volume in comparison with a hydrophilic surface area, they result in niosomes that are difficult to form. ${ }^{33}$ Hydration temperature is another crucial process variable in the preparation of niosomes. In order to prepare niosomes at a hydration temperature above the gel-liquid transition temperature $\left(\mathrm{T}_{\mathrm{c}}\right)$ of the surfactants, ${ }^{34}$ hydration was performed at $60^{\circ} \mathrm{C}, 70^{\circ} \mathrm{C}$, and $80^{\circ} \mathrm{C}$. The results showed that $60^{\circ} \mathrm{C}$ was the most suitable transition temperature. The niosomal formulation with a high cholesterol content (50\% of the total lipid content) was found to have

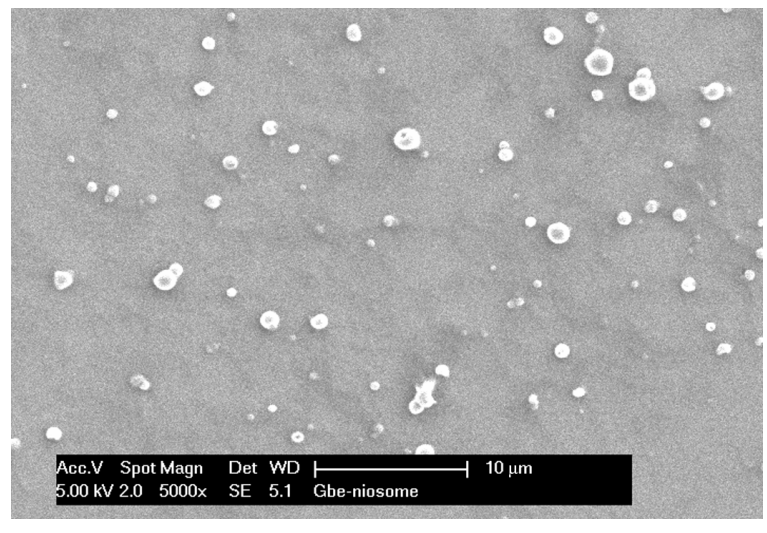

Figure I Scanning electron microscope images of GbEN.

high entrapment efficiency, and could be due to the improved stability of the niosomes achieved by addition of cholesterol, which has been reported to stabilize the bilayers, prevent leakage of drug components, and retard permeation of solutes enclosed in the aqueous core of niosomes. ${ }^{35}$ Table 1 shows that the preparation processes were controlled under appropriate conditions to obtain the optimal formulation. Although F1 was shown to achieve the highest entrapment efficiency in this study, the drug loading rate, which represents the drug content in the formulation, was the lowest $(9 \%, w / w)$. As a result, F10 was selected as the optimal niosomal formation due to the fact that it had a small particle size, relatively high entrapment efficiency, and the best drug loading rate.

\section{Characterization of GbE niosomes Morphology}

Scanning electron microscopy was used to investigate the morphology of the niosomes. Figure 1 shows that the niosomes were homogenous and had a spherical shape with a smooth surface. The images also confirmed that the niosomes were of nanometer size.

\section{Particle size, zeta potential, and entrapment efficiency}

The particle size of the niosomes (Table 2) was significantly increased from niosomal suspension to niosomal powder $(P<0.05)$ after addition of mannitol using both drying methods. There was no significant difference in particle

Table 2 Comparison of particle size, zeta potential and entrapment between different GbEN formulations $($ mean $\pm S D, n=3)$

\begin{tabular}{llll}
\hline Formulation & Particle size (nm) & Zeta potential (mV) & Entrapment efficiency (\%) \\
\hline Niosomal suspension & $141.3 \pm 11.9$ & $-0.1 \pm 1.7$ & $50.0 \pm 1.9$ \\
Niosomal powder by freeze-drying & $661.3 \pm 78.6$ & $-11.6 \pm 4.3$ & $50.1 \pm 1.0$ \\
Niosomal powder by spray-drying & $680.2 \pm 90.0$ & $-33.6 \pm 1.6$ & $77.5 \pm 1.0$ \\
\hline
\end{tabular}


Table 3 Angle of repose of niosomal powders (mean $\pm S D, n=3$ )

\begin{tabular}{llll}
\hline $\begin{array}{l}\text { Ratio of added } \\
\text { glidant to niosomal } \\
\text { powder }(\%)(w / w)\end{array}$ & \multicolumn{3}{l}{ Angle of repose (deg) } \\
\cline { 2 - 4 } & Aerosil & $\begin{array}{l}\text { Magnesium } \\
\text { stearate }\end{array}$ & $\begin{array}{l}\text { Microcrystalline } \\
\text { cellulose }\end{array}$ \\
\hline 0.2 & $34.3 \pm 1.7$ & $37.5 \pm 1.9$ & $31.0 \pm 1.4$ \\
1 & $32.3 \pm 2.3$ & $38.7 \pm 1.2$ & $32.3 \pm 0.9$ \\
2 & $36.9 \pm 1.2$ & $35.0 \pm 1.3$ & $35.0 \pm 1.3$ \\
3 & $36.3 \pm 0.8$ & $37.5 \pm 1.9$ & $34.4 \pm 2.2$ \\
5 & $38.7 \pm 2.4$ & $38.1 \pm 1.6$ & $36.3 \pm 2.1$ \\
Niosomal powder & $35.0 \pm 1.3$ & & \\
\hline
\end{tabular}

size between the freeze-dried powder and the spray-dried powder $(P>0.05)$. All of the formulations showed negative zeta potential values, which could reflect adsorption of counter ions or preferential adsorption of hydroxyl ions at the niosomal surface. ${ }^{36}$ The zeta potential was higher in the spray-dried niosomes than in the freeze-dried niosomes, indicating that the spray-dried niosomal powder was more stable against aggregation and fusion than the freeze-dried niosomal powder.

Various methods have been investigated to determine the entrapment efficiency of niosomes, including centrifugation, ${ }^{37}$ ultracentrifugation, ${ }^{38}$ dialysis, ${ }^{39}$ Sephadex gel filtration, ${ }^{40}$ ultrafiltration membrane filtration, ${ }^{41}$ and a macroporous adsorptive resins method. ${ }^{42}$ In our study, the ultracentrifugation and centrifugation methods were used to separate the free drug from the niosomal suspension and from the powder. No significant difference was found in drug entrapment efficiency between the niosomal suspension and the powder made by the freeze-drying method $(P>0.05)$. However, there was a significant difference in drug entrapment efficiency between the spray-drying (about 77.5\%) and the freeze-drying method (about $50.1 \%, P<0.05$ ). Therefore, spray-drying is the ideal method for preparing niosomal powder.
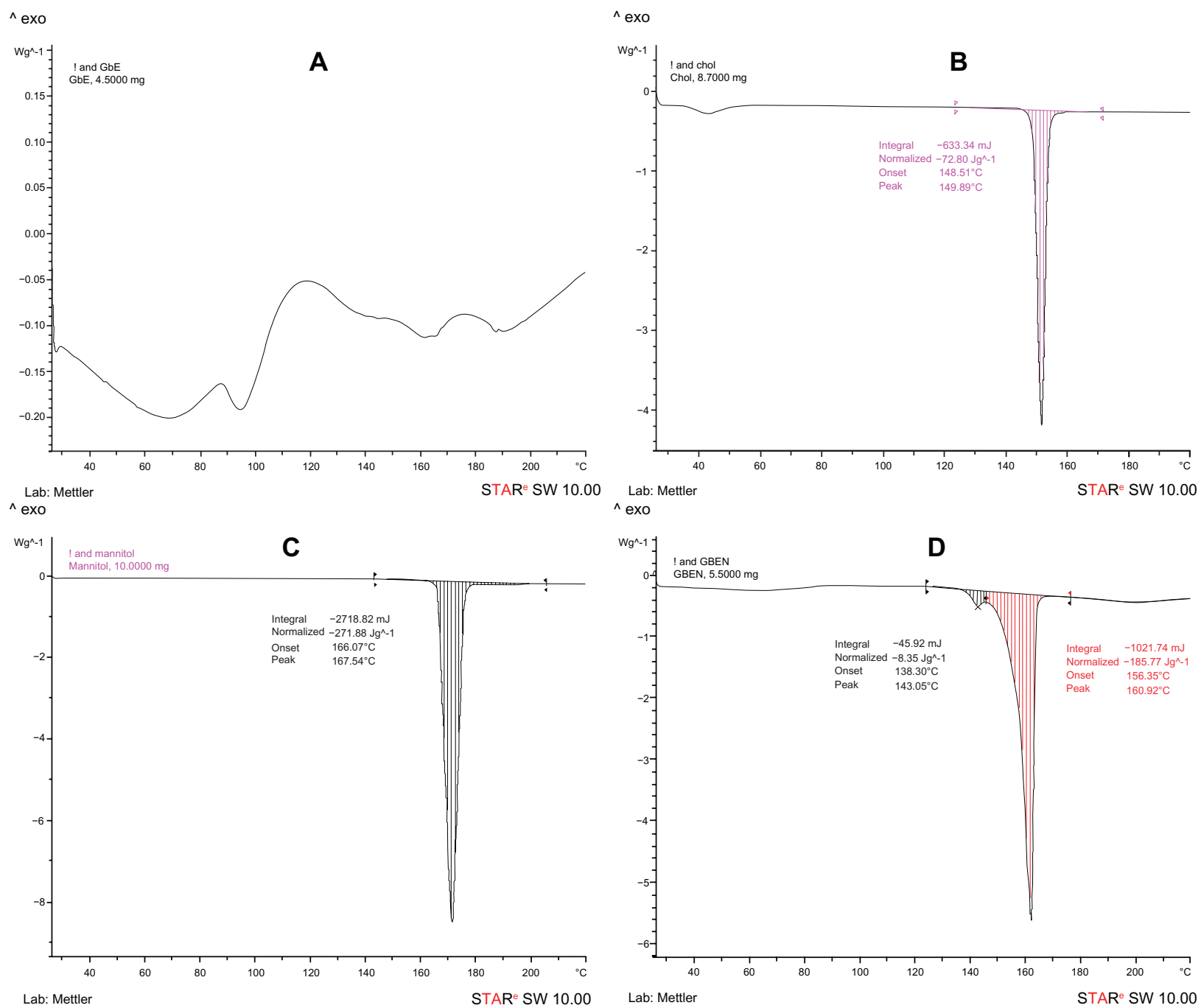

$\wedge$ exo

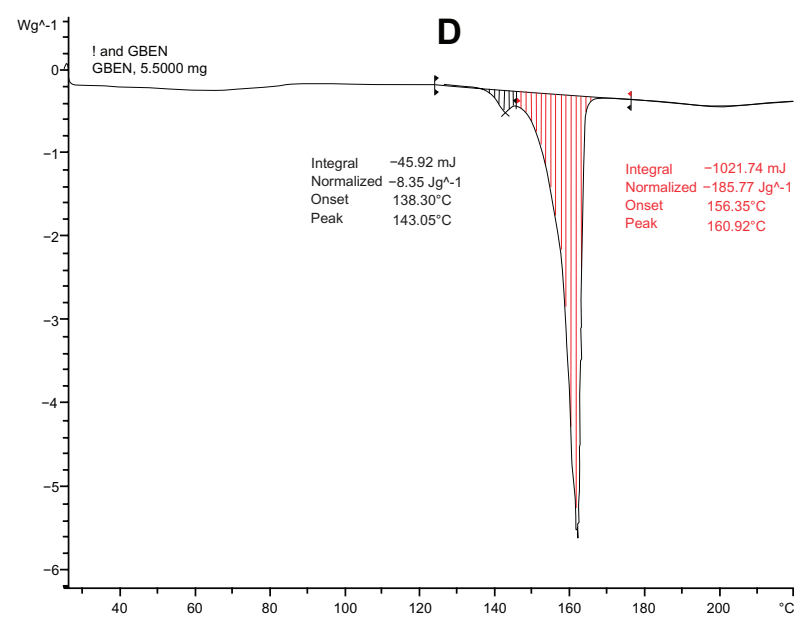

Lab: Mettler

STAR ${ }^{\mathrm{S}}$ SW 10.00

Figure 2 DSC curves. (A) DSC curve of GbE. (B) DSC curve of cholesterol. (C) DSC curve of mannitol. (D) DSC curve of GbEN. 


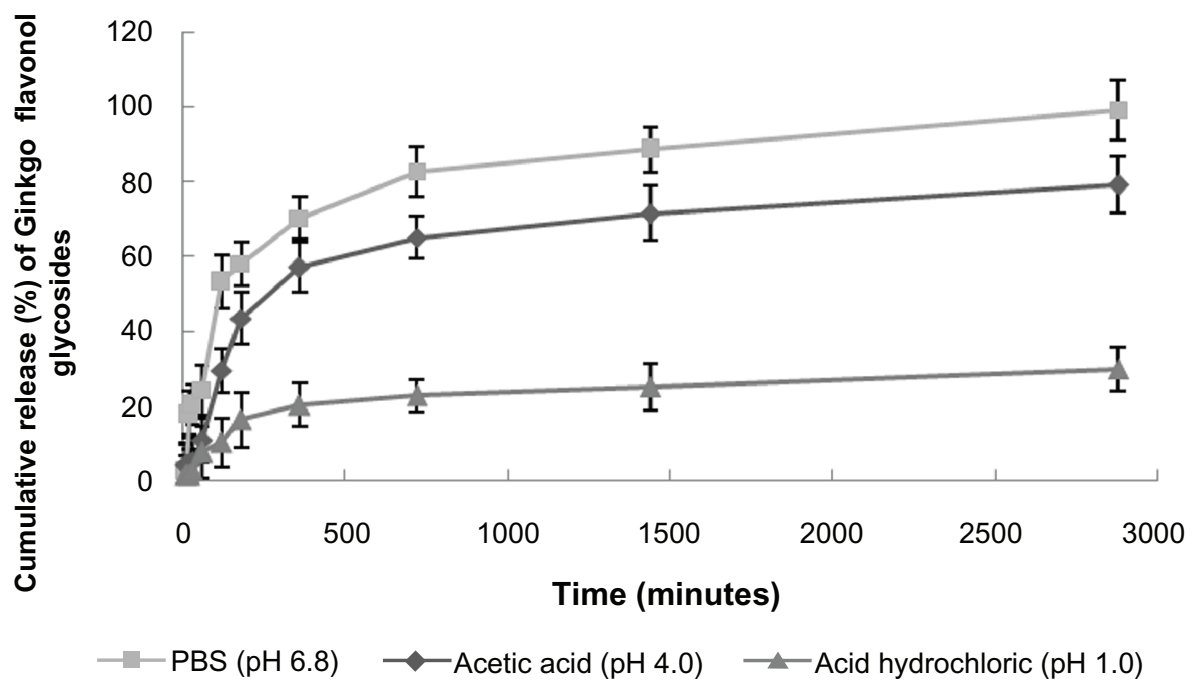

Figure 3 Release profiles of GbEN in various release media (mean $\pm S D, n=3$ ).

\section{Angle of repose}

Results for the angle of repose of the niosomal powder formulations are summarized in Table 3. When the proportion of glidants in the niosomal powder was increased, the angle of repose of the niosomal powder changed, which is consistent with a report by $\mathrm{Hu}$ and Rhodes. ${ }^{43}$ The results show that niosomal powder has free flow ability and can be processed further after addition of an appropriate glidant ( $0.2 \%$ microcrystalline cellulose, w/w) to the powder.

\section{Differential scanning calorimetry}

The DSC curves for GbE, cholesterol, mannitol, and the GbE niosomes are shown in Figure 2. As seen in Figure 2A, GbE showed four endothermal peaks because it is a mixture of compounds, which is in accordance with previous reports. ${ }^{44}$ The DSC curves for cholesterol (Figure 2B) and mannitol (Figure 2C), which were excipients in the GbE niosomes, showed apparent endothermal peaks at $149.89^{\circ} \mathrm{C}$ and $167.54^{\circ} \mathrm{C}$, respectively. Figure $2 \mathrm{D}$ shows that the DSC curve for the $\mathrm{GbE}$ niosomes had endothermal peaks at $143.05^{\circ} \mathrm{C}$ and $160.92^{\circ} \mathrm{C}$; the peaks of $\mathrm{GbE}$ disappeared and those of cholesterol and mannitol still existed except for a small change. It has been reported that $\mathrm{GbE}$ exists in the amorphous state when it does not show its endothermal peak in the formed niosome. ${ }^{45}$ Our results suggest that GbE was entrapped in the lipid bilayer of the niosomes and formed a new phase instead of being a simple physical mix between GbE and excipients.

\section{In vitro release studies}

The release profile (Figure 3) of flavonoid glycosides from the niosomes in the different types of medium was significantly different. All showed sustained release, with a rank order of the cumulative amount of flavonoid glycosides up to 48 hours in different media being phosphate buffer, pH 6.8 (approximately 100\%) > acetic acid solution, $\mathrm{pH} 4.0$ (approximately 80\%) $>\mathrm{HCl}$ solution, $\mathrm{pH} 1.0$ (approximately $30 \%$ ). These results could be due to the effects of $\mathrm{pH}$ on the release of $\mathrm{GbE}$, ie, cumulative drug release was less at a lower $\mathrm{pH}$ value. They also indicate that the niosome system may have the ability to protect the drug from being released in the stomach (where $\mathrm{pH}$ is close to 1.0), resulting in drug release in the lower parts of the intestinal tract (where $\mathrm{pH}$ is close to 6.8), meaning that the flavonoid glycosides from niosomes will be better absorbed at this site.

Table 4 shows that all release curves are well fitted to a Korsmeyer-Peppas model, with all regression coefficients $\left(r^{2}\right)$ above 0.87 in the different types of release medium.

Table 4 Release kinetic parameters of GbEN in various release media

\begin{tabular}{|c|c|c|c|c|c|c|c|c|}
\hline \multirow[t]{2}{*}{ Release medium } & \multicolumn{2}{|c|}{ Zero order } & \multicolumn{2}{|c|}{ First order } & \multicolumn{2}{|c|}{ Higuchi model } & \multicolumn{2}{|c|}{ Korsmeyer-Peppas model } \\
\hline & $r^{2}$ & k & $r^{2}$ & k & $r^{2}$ & k & $r^{2}$ & k \\
\hline PBS (pH 6.8) & 0.5864 & 0.0305 & 0.2684 & 0.0004 & 0.8248 & 1.9383 & 0.8689 & 0.6047 \\
\hline Acetic acid ( $\mathrm{pH} 4.0)$ & 0.6186 & 0.0268 & 0.3719 & 0.0004 & 0.8465 & 1.6811 & 0.9409 & 0.6139 \\
\hline $\mathrm{HCl}(\mathrm{pH} \mathrm{I.0)}$ & 0.6484 & 0.0097 & 0.3945 & 0.0004 & 0.8677 & 0.6023 & 0.8972 & 0.5211 \\
\hline
\end{tabular}


Table 5 Stability studies of GbEN at different temperatures

\begin{tabular}{|c|c|c|}
\hline Month & $\begin{array}{l}\text { Entrapment efficiency of } \\
\text { niosome at } 4^{\circ} \mathrm{C}-8^{\circ} \mathrm{C}(\%)\end{array}$ & $\begin{array}{l}\text { Entrapment efficiency of } \\
\text { niosome at } 25^{\circ} \mathrm{C} \pm 2^{\circ} \mathrm{C}(\%)\end{array}$ \\
\hline 0 & $77.50 \pm 1.00$ & $77.50 \pm 1.00$ \\
\hline I & $76.72 \pm 1.07$ & $77.06 \pm 1.08$ \\
\hline 2 & $76.90 \pm 0.94$ & $76.90 \pm 1.25$ \\
\hline 3 & $75.39 \pm 1.11$ & $75.38 \pm 0.87$ \\
\hline
\end{tabular}

Overall, the in vitro release data indicate that $\mathrm{GbE}$ niosomes can sustain drug release over time.

\section{Stability studies}

Stability studies for the niosomal powder were performed by storage at $4^{\circ} \mathrm{C}-8^{\circ} \mathrm{C}$ and $25^{\circ} \mathrm{C} \pm 2^{\circ} \mathrm{C}$ for a period of 3 months. The entrapment efficiency of the flavonoid glycosides in the niosomes was determined at the end of each month. There was no significant change in entrapment efficiency for the $\mathrm{GbE}$ niosomes at these two temperatures after 3 months $(P>0.05$, Table 5$)$. Hence, niosomes could represent an effective formulation to protect drug leakage from the formulation.

\section{In vivo distribution of $\mathrm{GbE}$ niosomes in the rat}

The flavonoid glycoside content in rodent organs and tissues was evaluated by HPLC. The results (Table 6) show that the flavonoid glycoside content in the rat heart, lung, kidney, and brain was significantly higher in the GbE niosome group than in the GbE tablet group $(P<0.05)$. Interestingly, there was a certain amount of flavonoid glycosides found in the brain in the $\mathrm{GbE}$ niosome group, but there were no flavonoid glycosides detected in the brain of the GbE tablet group. In the GbE tablet group, flavonoid glycosides were taken up to a considerable degree by the liver. This could be explained by the fact that GbE niosomes have more affinity for being deposited in the

Table 6 The concentrations of flavonoid glycosides in rats' organs and tissues (mean $\pm S D, n=10$ )

\begin{tabular}{lll}
\hline Organ and tissue & $\begin{array}{l}\text { GbEN group } \\
(\mu \mathrm{g} / \mathrm{mL})\end{array}$ & $\begin{array}{l}\text { GbE tablet group } \\
(\mu \mathrm{g} / \mathrm{mL})\end{array}$ \\
\hline Heart & $0.3288 \pm 0.0052^{* * *}$ & $0.0982 \pm 0.0178$ \\
Liver & $0.5139 \pm 0.0018^{* * *}$ & $0.6397 \pm 0.0162$ \\
Spleen & $0.2657 \pm 0.0040^{* * *}$ & $0.2309 \pm 0.0084$ \\
Lung & $0.5496 \pm 0.0066 * * *$ & $0.2339 \pm 0.0036$ \\
Kidney & $0.4797 \pm 0.0088^{* * *}$ & $0.1013 \pm 0.0028$ \\
Brain & $0.3401 \pm 0.0047^{* * *}$ & - \\
Blood & $0.8179 \pm 0.0102^{* * *}$ & $0.6948 \pm 0.0146$ \\
\hline
\end{tabular}

Notes: Compared with GbE tablet group; ***P $<0.001$. brain by masking their physicochemical characteristics and may avoid phagocytosis in the endothelial system. The concentration of drug in rat blood was also higher in the GbE niosome group than in the GbE group, which may be because the niosomes had a prolonged retention time in vivo, resulting in a stable blood concentration. Several reports have shown that the bioavailability of drugs can be improved $^{46,47}$ due to altered pharmacokinetic behavior and in vivo distribution, and higher accumulation in the brain would be useful when using GbE as pharmacotherapy for diseases affecting the brain.

\section{Conclusion}

A novel niosomal delivery system loaded with G. biloba flavonoid glycosides was developed and characterized in this study. Several factors, including surfactant content, hydrophile-lipophile balance value, hydration temperature, and cholesterol content were optimized to obtain an ideal formulation with high entrapment efficiency and relatively small particle size. The conditions for preparing the optimal niosome suspension included surfactants and cholesterol at a molar ratio of $1: 1, \mathrm{GbE}$ and carrier at a weight ratio of 15:100, a hydrophile-lipophile balance of 11, and a hydration temperature of $60^{\circ} \mathrm{C}$. In order to prevent drug degradation, fusion, and leakage, the niosomal suspension was further developed to form niosomal powder by freezedrying and spray-drying methods. After characterization of the niosomal powders for characteristics including particle size, zeta potential, and entrapment efficiency, the spray-drying method was selected as the best preparation technique. The morphology, angle of repose, and DSC were also evaluated for the GbE niosomes. The release study showed that the niosomes were able to prolong the release of flavonoid glycosides for up to 48 hours in phosphate-buffered solution ( $\mathrm{pH}$ 6.8). Niosomal powder may serve as a suitable carrier for $\mathrm{GbE}$ because of its good stability over 3 months at two temperatures $\left(4^{\circ} \mathrm{C}-8^{\circ} \mathrm{C}\right.$ and $25^{\circ} \mathrm{C} \pm 2^{\circ} \mathrm{C}$ ).

The in vivo distribution results suggest that niosomes have an obvious ability to increase drug content in the rat heart, lung, kidney, brain, and blood compared with tablets. It can be inferred that niosomes have the ability to help in transport of flavonoid glycosides to the brain and to avoid phagocytosis by the endothelial system in the liver. In summary, niosomes offer an effective and practical means of delivering the GbE to the brain via oral administration and thus could prove to be a good alternative to conventional formulations. 


\section{Disclosure}

The authors declare that they have no competing financial interests in this work.

\section{References}

1. Singh B, Kaur P, Gopichand, Singh RD, Ahuja PS. Biology and chemistry of ginkgo biloba. Fitoterapia. 2008;79:401-418.

2. Ellnain-Wojtaszek M, Kruczyński Z, Kasprzak J. Investigation of the free radical scavenging activity of ginkgo biloba 1 . Leaves. Fitoterapia. 2003;74:1-6.

3. Goh LM, Barlow PJ, Yong CS. Examination of antioxidant activity of Ginkgo biloba leaf infusions. Food Chem. 2003;82:275-282.

4. Kawaii S, Tomono Y, Katase E, Ogawa K, Yano M. Antiproliferative activity of flavonoids on several cancer cell lines. Biosci Biotechnol Biochem. 1999;63:896-899.

5. Oyama Y, Chikahisa L, Ueha T, Kanemaru K, Noda K. Ginkgo biloba extract protects brain neurons against oxidative stress induced by hydrogen peroxide. Brain Res. 1996;712:349-352.

6. Oken BS, Storzbach DM, Kaye JA. The efficacy of Ginkgo biloba on cognitive function in Alzheimer disease. Arch Neurol. 1998;55: 1409-1415.

7. van Dongen M, van Rossum E, Kessels A, Sielhorst H, Knipschild P. Ginkgo for elderly people with dementia and age-associated memory impairment: a randomized clinical trial. J Clin Epidemiol. 2003;56: 367-376.

8. Burschka MA, Hassan HA, Reineke T, van Bebber L, Caird DM, Mösges R. Effect of treatment with Ginkgo biloba extract EGB 761 (oral) on unilateral idiopathic sudden hearing loss in a prospective randomized double-blind study of 106 outpatients. Eur Arch Otorhinolaryngol. 2001;258:213-219.

9. van Beek TA. Chemical analysis of Ginkgo biloba leaves and extracts. J Chromatogr A. 2002;967:21-55.

10. Mesbah MK, Khalifa SI, El-Gindy A, Tawfik KA. Hplc determination of certain flavonoids and terpene lactones in selected Ginkgo biloba L. Phytopharmaceuticals. Farmaco. 2005;60:583-590.

11. Drago F, Floriddia ML, Cro M, Giuffrida S. Pharmacokinetics and bioavailability of a ginkgo biloba extract. J Ocul Pharmacol Ther. 2002;18:197-202.

12. Yamamoto S, Nakano K, Ishikawa C, et al. Enhanced inhibitory effects of extracts from ginkgo biloba L. Leaves encapsulated in hybrid liposomes on the growth of tumor cells in vitro. Biochem Eng J. 2002;12:125-130.

13. Chen ZP, Sun J, Chen HX, et al. Comparative pharmacokinetics and bioavailability studies of quercetin, kaempferol and isorhamnetin after oral administration of ginkgo biloba extracts, ginkgo biloba extract phospholipid complexes and ginkgo biloba extract solid dispersions in rats. Fitoterapia. 2010;81:1045-1052.

14. Garcia-Garcia E, Andrieux K, Gil S, Couvreur P. Colloidal carriers and blood-brain barrier (BBB) translocation: a way to deliver drugs to the brain? Int J Pharm. 2005;298:274-292.

15. Manosroi A, Wongtrakul P, Manosroi J, et al. Characterization of vesicles prepared with various non-ionic surfactants mixed with cholesterol. Colloids Surf B Biointerfaces. 2003;30:129-138.

16. Uchegbu IF, Vyas SP. Non-ionic surfactant based vesicles (niosomes) in drug delivery. Int J Pharm. 1998;172:33-70.

17. Vora B, Khopade AJ, Jain NK. Proniosome based transdermal delivery of levonorgestrel for effective contraception. J Control Release. 1998;54:149-165.

18. Sinha V, Singh A, Kumar RV, Singh S, Kumria R, Bhinge J. Niosomes for oral delivery of peptide drugs. J Control Release. 1992;21:145-153.

19. Terzano C, Allegra L, Alhaique F, Marianecci C, Carafa M. Non-phospholipid vesicles for pulmonary glucocorticoid delivery. Eur J Pharm Biopharm. 2005;59:57-62.

20. Manosroi A, Jantrawut P, Manosroi J. Anti-inflammatory activity of gel containing novel elastic niosomes entrapped with diclofenac. Int $J$ Pharm. 2008;360:156-163.
21. Pardakhty A, Varshosaz J, Rouholamini A. In vitro study of polyoxyethylene alkyl ether niosomes for delivery of insulin. Int $J$ Pharm. 2007;328:130-141.

22. Farkas E, Schubert R, Zelkó R. Effect of $\beta$-sitosterol on the characteristics of vesiculargels containing chlorhexidine. Int J Pharm. 2004;278:63-70.

23. Walker W, Brewer JM, Alexander J. Lipid vesicle-entrapped influenza a antigen modulates the influenza A-specific human antibody response in immune reconstituted scid-human mice. Eur J Immunol. 1996;26: 1664-1667.

24. Manconi M, Sinico C, Valenti D, Loy G, Fadda AM. Niosomes as carriers for tretinoin. I. Preparation and properties. Int $J$ Pharm. 2002;234:237-248.

25. Gupta A, Prajapati SK, Singh M, Balamurugan M. Proniosomal powder of captopril: formulation and evaluation. Mol Pharm. 2007;4:596-599.

26. Mukherjee B, Patra B, Layek B, Mukherjee A. Sustained release of acyclovir from nano-liposomes and nano-niosomes: an in vitro study. Int J Nanomedicine. 2007;2:213-225.

27. Arunothayanun P, Bernard MS, Craig DQ, Uchegbu IF, Florence AT. The effect of processing variables on the physical characteristics of non-ionic surfactant vesicles (niosomes) formed from a hexadecyl diglycerol ether. Int J Pharm. 2000;201:7-14.

28. Fang JY, Yu SY, Wu PC, Huang YB, Tsai YH. In vitro skin permeation of estradiol from various proniosome formulations. Int J Pharm. 2001;215:91-99.

29. Tank CJ, Borkhataria $\mathrm{CH}$, Baria AH, Patel RP. Formulation and evaluation of aceclofenac loaded maltodextrin based proniosome. International Journal of ChemTech Research. 2009;1:567-573.

30. Klajnert B, Janiszewska J, Urbanczyk-Lipkowska Z, Bryszewska M, Epand RM. DSC studies on interactions between low molecular mass peptide dendrimers and model lipid membranes. Int J Pharm. 2006;327: $145-152$.

31. Saarinen-Savolainen P, Jarvinen T, Taipale H, Urtti A. Method for evaluating drug release from liposomes in sink conditions. Int J Pharm. 1997;159:27-33.

32. Shahiwala A, Misra A. Studies in topical application of niosomally entrapped nimesulide. J Pharm Pharm Sci. 2002;5:220-225.

33. Parthasarathi G, Udupa N, Umadevi P, Pillai GK. Niosome encapsulated of vincristine sulfate: improved anticancer activity with reduced toxicity in mice. J Drug Target. 1994;2:173-182.

34. Arunothayanun P, Uchegbu IF, Craig DQ, Turton JA, Florence AT. In vitro/in vivo characterisation of polyhedral niosomes. Int $J$ Pharm. 1999;183:57-61.

35. Devaraj GN, Parakh SR, Devraj R, Apte SS, Rao BR, Rambhau D. Release studies on niosomes containing fatty alcohols as bilayer stabilizers instead of cholesterol. J Colloid Interface Sci. 2002;251:360-365.

36. Junyaprasert VB, Teeranachaideekul V, Supaperm T. Effect of charged and non-ionic membrane additives on physicochemical properties and stability of niosomes. AAPS Pharm Sci Tech. 2008;9:851-859.

37. Naresh A, Vipin S, Vijay KB, et al. Formulation and evaluation of lansoprazole niosome. Rasayan Journal of Chemistry. 2008;1: $561-563$.

38. Guinedi AS, Mortada ND, Mansour S, Hathout RM. Preparation and evaluation of reverse-phase evaporation and multilamellar niosomes as ophthalmic carriers of acetazolamide. Int J Pharm. 2005;306:71-82.

39. Srinivas S, Kumar YA, Hemanth A, Anitha M. Preparation and evaluation of niosomes containing aceclofenac. Digest Journal of Nanomaterials and Biostructures. 2010;5:249-254.

40. Fry DW, White JC, Goldman ID. Rapid separation of low molecular weight solutes from liposomes without dilution. Anal Biochem. 1978;90: 809-815.

41. Sun W-T, Huang G, Ye J-S, Zhang N. Determination of encapsulation efficiencies of liposomes and nanoliposomes by protamine aggregation method. Chinese Pharmaceutical Journal. 2006;41:1716-1719.

42. Suo X-B, Deng Y-J, Jing S-Q, et al. Determination of the entrapment efficiency of astragaloside liposome with HPLC-ELSD and macroreticular resin. Chinese Pharmaceutical Journal. 2004;40: $680-681$. 
43. Hu C, Rhodes DG. Proniosomes: A novel drug carrier preparation. Int J Pharm. 1999;185:23-35.

44. GeY. An investigation into the mechanisms of rapid release of standard extract from ginkgo biloba leaf in polyethylene glycol 6000 solid dispersions. Yakugaku Zasshi. 2010;130:425-430.

45. Wang M, Yuan Y, Gao Y, et al. Preparation and characterization of 5-fluorouracil $\mathrm{pH}$-sensitive niosome and its tumor-targeted evaluation: in vitro and in vivo. Drug Dev Ind Pharm. 2012;38:1134-1141.
46. Lalloo A, Chao P, Hu P, Stein S, Sinko PJ. Pharmacokinetic and pharmacodynamic evaluation of a novel in situ forming poly(ethylene glycol)-based hydrogel for the controlled delivery of the camptothecins. J Control Release. 2006;112:333-342.

47. Teixeira RS, Curi R, Maranhão RC. Effects on Walker 256 tumour of carmustine associated with a cholesterol-rich microemulsion (LDE). J Pharm Pharmacol. 2004;56:909-914.

\section{Publish your work in this journal}

The International Journal of Nanomedicine is an international, peerreviewed journal focusing on the application of nanotechnology in diagnostics, therapeutics, and drug delivery systems throughout the biomedical field. This journal is indexed on PubMed Central, MedLine, CAS, SciSearch ${ }^{\circledR}$, Current Contents ${ }^{\circledR} /$ Clinical Medicine,
Journal Citation Reports/Science Edition, EMBase, Scopus and the Elsevier Bibliographic databases. The manuscript management system is completely online and includes a very quick and fair peer-review system, which is all easy to use. Visit http://www.dovepress.com/ testimonials.php to read real quotes from published authors.

Submit your manuscript here: http://www.dovepress.com/international-journal-of-nanomedicine-journal 